\title{
Prognostic role of ERBB2, MET and VEGFA expression in metastatic colorectal cancer patients treated with anti-EGFR antibodies
}

\author{
Naoki Takahashi ${ }^{*}, 1$, Satoru Iwasa ${ }^{1}$, Hirokazu Taniguchi ${ }^{2}$, Yusuke Sasaki ${ }^{1}$, Hirokazu Shoji ${ }^{1}$, \\ Yoshitaka Honma ${ }^{1}$, Atsuo Takashima ${ }^{1}$, Natsuko Okita ${ }^{1}$, Ken Kato ${ }^{1}$, Tetsuya Hamaguchi ${ }^{1}$, Yasuhiro Shimada ${ }^{1}$ \\ and Yasuhide Yamada*,1 \\ ${ }^{1}$ Gastrointestinal Medical Oncology Division, National Cancer Center Hospital, 5-1-1 Tsukiji, Chuo-ku, Tokyo, 104-0045, Japan and \\ ${ }^{2}$ Pathology and Clinical Laboratory Division, National Cancer Center Hospital, 5-1-1 Tsukiji, Chuo-ku, Tokyo, 104-0045, Japan
}

\begin{abstract}
Background: High amplification of epiregulin (EREG) and amphireglin (AREG) in tumour tissues has been previously reported to be associated with better outcome in metastatic colorectal cancer (mCRC) patients who were treated with anti-EGFR antibodies. Here we investigated associations between the expression of other candidate prognostic biomarkers and outcome in $\mathrm{mCRC}$ patients receiving similar treatment.
\end{abstract}

Methods: The relative mRNA levels of seven genes including ERBB2, MET, VEGFA, EREG, AREG, PTEN and ERCC1 between tumour (T) and non-tumour (NT) tissue sections were analysed by quantitative real-time PCR. Relative mRNA values, that is, T/NT ratios, of target genes were calculated and hazard ratios (HRs) for each gene of interest were adjusted for age, gender, performance status, minor RAS mutations and other clinicopathological variables which exhibited $P$-values $<0.1$ on the basis of univariate analysis.

Results: Among 108 cases who received anti-EGFR antibodies, there were 96 cases of KRAS exon2 wild-type patients enroled in this study. When the cutoff values for relative mRNA levels were set to the upper 25th percentile of all patients, there were statistically significant differences in overall survival (OS) between the patients with high and low levels of EREG (HR: $0.326,95 \% \mathrm{Cl}$ : 0.136-0.772, $P=0.011$ ), ERBB2 (HR: 1.31, 95\% Cl: 1.084-1.652, $P=0.040)$, MET (HR: 2.48, 95\% Cl: 1.356-5.463, $P=0.026$ ), and VEGFA (HR: 1.29, 95\% Cl: 1.036-1.606, $P=0.046)$. In addition, patients with high ERBB2 had shorter progression-free survival (PFS) compared with low ERBB2 (HR: 1.98, 95\% Cl: 1.062-3.850). There were no significant differences in PFS and OS with respect to relative expression levels of PTEN and ERCC1. The prognostic role of AREG was evaluated in only T sections, as the mRNA expression level of this gene was mostly ( $91 \%$ cases) undetectable in NT sections. Patients with high AREG had longer OS compared with low AREG (HR: 0.227, 95\% Cl: 0.095-0.808).

Conclusions: Our study has shown that higher T/NT ratios of ERBB2, MET and VEGFA mRNA were associated with worse OS in $\mathrm{mCRC}$ patients treated with anti-EGFR antibodies, with higher EREG and AREG were associated with better prognosis in the same setting. These findings will contribute the further understanding and management of anti-EGFR antibody treatment in mCRC patients.

*Correspondence: Dr N Takahashi; E-mail: naoki19800623@gmail.com or Dr Y Yamada; E-mail: yasuhide-yamada@amed.go.jp 
Colorectal cancer (CRC) is the second most common cause of cancer in women, and the third most common in men and the fourth leading cause of cancer deaths worldwide (Jemal et al, 2011). Owning to the development and use of several cytotoxic drugs and molecularly target agents, overall survival in metastatic CRC patients has significantly improved over the last decade.

The therapeutic use of anti-epidermal growth factor receptor (EGFR) monoclonal antibodies is approved in metastatic CRC, with mutation of KRAS exon2 being recognised as a strong predictive factor for no clinical benefit of anti-EGFR antibody treatment (Jonker et al, 2007; Van Cutsem et al, 2009; Douillard et al, 2010). Anti-EGFR antibodies comprised cetuximab and panitumumab, and these drugs were confirmed to provide similar outcome improvements and adverse events as determined in a randomised phase III trial (Price et al, 2014). Recently, genetic analyses of prospective trials indicated that RAS mutation, which consists of KRAS (exon 2,3 and 4) and NRAS (exon 2, 3 and 4) mutations, is a newly identified predictive biomarker for no clinical benefit of anti-EGFR antibody treatment in metastatic CRC (Douillard et al, 2013; Van Cutsem et al, 2015). Taking into account key factors involved in the EGFR downstream signalling pathway, BRAF V600E mutation was previously reported as a prognostic factor in anti-EGFR antibody treatment of patients with metastatic CRC (Van Cutsem et al, 2011). Moreover, the PTEN/ $\mathrm{PI} 3 \mathrm{~K} / \mathrm{AKT}$ axis is an important EGFR downstream signalling pathway regulating multiple biological processes such as apoptosis, metabolism, cell proliferation and cell growth (Blanco-Aparicio et al, 2007). The loss of PTEN expression was previously reported as a poor prognostic factor in respect to treatment with anti-EGFR antibodies in patients with metastatic CRC (Loupakis et al, 2009).

Further biomarker analyses in relation to anti-EGFR antibody response in metastatic CRC beyond RAS mutation has been performed. In several reports, high expression of epiregulin (EREG) and amphiregulin (AREG) in tumour tissues was associated with better outcome following treatment with cetuximab in metastatic CRC patients (Khambata-Ford et al, 2007; Jacobs et al, 2009; Jonker et al, 2014). In addition, there have been a few previous reports to evaluate the prognostic value of ERBB2, VEGFA and MET expression in chemotherapy-refractory metastatic CRC patients who were treated with anti-EGFR antibodies. ERBB2 (HER2) is known as a member of the ErbB family of receptor tyrosine kinases. HER2 status in tumour tissue an important determinant of whether HER2-targeted agents should be used in patients with breast cancer and gastric or gastrooesophageal junction adenocarcinoma (Slamon et al, 2001; Bang et al, 2010). The hepatocyte growth factor/scatter factor (HGF/SF) and MET receptor signalling pathway elicits multiple cellular responses regulating cell survival, morphogenesis, adhesion, migration, breakdown of extracellular matrix and angiogenesis (Birchmeier et al, 2003; Lesko and Majka 2008). Vascular endothelial growth factor-A (VEGFA) has a key role in tumour angiogenesis and is a molecular target of anti-VEGF antibodies such as bevacizumab, which is used as first- or second-line treatment for metastatic CRC patients (Hurwitz et al, 2004; Saltz et al, 2008). On the other hand, the role of VEGFA as a biomarker of anti-EGFR antibody treatment in metastatic CRC patients is unclear.

There are no established predictive or prognostic markers for use in clinical practice beyond RAS or BRAF mutations in respect to the treatment with anti-EGFR antibodies in metastatic CRC. In the present study, we selected several genes encoding receptor tyrosine kinases (RTKs), ligands and EGFR downstream molecules as candidate biomarkers of resistance to anti-EGFR antibody use or therapeutic targets of dual-target therapy with anti-EGFR antibody treatment in RAS wild-type patients. We analysed the relative mRNA values of each of these genes by using tumour $(\mathrm{T})$ and nontumour (NT) tissues sections from the same patient, that is, T/NT ratio, to determine the prognostic value of expression of these genes with respect to treatment of metastatic CRC patients with anti-EGFR antibodies.

MATERIALS AND METHODS

Patients and sample collection. We collected 108 cases of formalin-fixed paraffin-embedded (FFPE) tumour samples from metastatic CRC patients who were treated with anti-EGFR antibodies for genetic analyses. We enrolled 96 KRAS exon2 wild-type patients who met the following inclusion criteria: pathologically proven adenocarcinoma, metastatic or recurrent colorectal cancer, an Eastern Cooperative Oncology Group (ECOG) Performance status (PS) of 0 to 2, patients who had previously received one or more standard regimens of systemic chemotherapy, adequate amount of tissue samples for quantitative real-time PCR (qRT-PCR) analyses, no significant abnormality in terms of liver and renal function, patients who received a combination of irinotecan and anti-EGFR antibodies or monotherapy with anti-EGFR antibodies. The main exclusion criteria included the following: previous chemotherapy targeting the EGF pathway, other duplicated advanced cancer and metastasis to the central nervous system. Patients continued to receive chemotherapy until disease progression or intolerable toxicity from chemotherapy intervened. The response was evaluated by contrast-enhanced computed tomography every 2 to 3 months. Patient consent for the use of clinical materials was obtained, and this study was undertaken after approval by the National Cancer Center Institutional Review Board.

Extraction of RNA and qRT-PCR analysis. Total RNA (included miRNA) was extracted from T and NT tissue section in same FFPE slides using the miRNeasy FFPE Kit (QIAGEN KK, Tokyo, Japan). The extracted RNA was stocked at $-80^{\circ} \mathrm{C}$ until use. cDNA was synthesised using PrimeScriptRT MasterMix (Perfect Real Time, Takara Bio Inc., Otsu, Japan). Quantitative real-time PCR was performed in a Thermal Cycler Dice Real-time System TP800 (Takara Bio Inc., Otsu, Japan) using SYBR Premix Ex Taq II (Tli RNaseH Plus, Takara Bio Inc., Otsu, Japan). Quantitative real-time PCR (forward and reverse) used Perfect Real Time Primer (Takara Bio Inc., Otsu, Japan). The primers used for qRT-PCR are summarised in Supplementary Material 1. Relative mRNA values as $\mathrm{T} / \mathrm{NT}$ ratio of target genes in same tissues were calculated to evaluate how level of mRNA expression of T sections were higher compared with that of NT section in each patient. Glyceraldehyde 3-phosphate dehydrogenase $(G A P D H)$ was used as a reference gene to correct for differences in terms of both quality and quantity between samples. The relative quantity of AREG, EREG, ERBB2, MET, VEGFA, PTEN and ERCC1 mRNA in both $\mathrm{T}$ and NT sections was normalised to the level of the internal control GAPDH mRNA and were expressed as 'tumour ddCt Rel Qty/non-tumour ddCt Rel Qty' where dCt is the difference between the gene of the target and the GAPDH gene, and ddCT is the difference between the dCT for each sample and the control group.

Direct sequencing of KRAS, BRAF, PIK3CA and NRAS. DNA samples were extracted from FFPE tumour tissue sections. Tumour cell-rich areas within $\mathrm{H} \& \mathrm{E}$-stained sections were marked under a microscope, and tissue was scraped from the corresponding areas of additional deparaffinised unstained sections. DNA from the scraped-off tissue sample was isolated using the QIAamp DNA FFPE Tissue Kit (QIAGEN KK, Tokyo, Japan). Exon 2 (codons 12 and 13), exon 3 (codon 61), exon 4 (codon 146) of the KRAS gene and exon 15 (codon 600) of the BRAF gene and exon 9 (codons 542 and 545), exon 20 (codon 1047) of the PIK3CA gene and exon 2 (codons 12 and 13), exon 3 (codon 61) of the NRAS gene were amplified by PCR (the GeneAmp PCR System 9700 thermal cycler (Life Technologies Japan (Applied Biosystems), Tokyo, Japan)). 
The methods utilised for genetic analyses of KRAS, NRAS, BRAF and PIK3CA were as described previously (Takahashi et al, 2014).

Assessment and statistical analysis. To assess associations of relative gene expression levels with the objective response rate (ORR), disease control rate (DCR), progression-free survival (PFS) and overall survival (OS), the values for each gene were categorised into low and high levels with respect to the several cut-off values. Assessment of therapeutic response consisted of complete response $(\mathrm{CR})$, partial response (PR), stable disease (SD), disease progression (PD), and not evaluated (NE), according to the Response Evaluation Criteria in Solid Tumours (RECIST) ver. 1.1. ORR was defined as the proportion of patients whose best response was a CR or PR among all patients. OS was defined as the interval from initiation of anti-EGFR therapy to death or last follow-up.

Differences in the distribution of variables were evaluated using Fisher's exact test or $\chi^{2}$-test, as appropriate. Progression-free survival and OS were estimated by the Kaplan-Meier method and survival curves were compared by the log-rank test. We estimated hazard ratios (HRs) and the corresponding 95\% confidence intervals (CIs) for PFS and OS using univariate and multivariate analysis by Cox proportional hazards model. Relevant clinicopathological variables included age $(\leqslant 60 v s>60)$, gender (male $v s$ female), ECOG PS (0-1 vs 2), histological type (differentiated $v s$ undifferentiated), primary site (colon $v s$ rectum), stage (stage IV $v s$ recurrence), number of metastatic sites ( 1 vs 2 or more), resection of primary site (yes $v s$ no), metastatic sites (liver metastasis and peritoneal dissemination), anti-EGFR antibody (cetuximab vs panitumumab), treatment (combination $v s$ monotherapy), minor KRAS/NRAS mutations (yes vs no). Adjusted HRs for ERBB2, $M E T, V E G F A, P T E N, E R C C 1, E R E G$ and AREG gene expression levels were determined according to age, gender, performance status, minor RAS mutations and other clinicopathological variables, which displayed $P$-values $<0.1$ from the univariate analysis. Receiver operating characteristics curve analysis was performed to determine the optimal cutoff values for each gene as continuous variables. All tests were two-sided and a $P$-value $<0.05$ was defined as statistically significant. We performed statistical analyses via use of SPSS statistical software, version 19 (IBM, Tokyo, Japan).

\section{RESULTS}

Among 108 patients who were treated with anti-EGFR antibodies, a total of 96 KRAS exon 2 wild-type patients met the selection criteria between August 2008 and August 2011 in our institution. The patient characteristics of this cohort are summarised in Table 1. The median age was 61 years old, and the histological tumour types comprised differentiated $(89.6 \%)$ and undifferentiated (10.4\%) adenocarcinoma. Most patients (96.9\%) underwent prior resection of the primary site. Seventy patients (80.2\%) were treated with irinotecan-based chemotherapy plus anti-EGFR antibody and others (19.8\%) were treated with anti-EGFR antibody monotherapy. Thirty-two patients $(31.1 \%)$ received subsequent treatment after failure of anti-EGFR antibodies. With respect to occurrence of minor KRAS and NRAS alternations, gene mutations in KRAS codon $61(n=2)$, KRAS codon $146(n=2)$, NRAS codon $13(n=3)$ and NRAS codon $61(n=2)$ were detected. In addition, $B R A F$ V600E mutation was detected in two patients.

Distribution of relative mRNA levels for each gene of interest. The relative mRNA values for each gene of interest are shown in Table 2. Median values of ERBB2 $(n=58)$, MET $(n=60)$, PTEN $(n=65)$, VEGFA $(n=78)$, ERCC $1(n=80)$ and EREG $(n=60)$ were 0.62 (measurable range: $0.0011-32.228), 0.905 \quad(0.030-$ $568.165), \quad 0.688$ (0.0040-17.875), 0.69 (0.00031-33.823), 0.486 (0.0015-75.059) and $0.408(0.00025-216.747)$, respectively. The
Table 1. Patients' characteristics

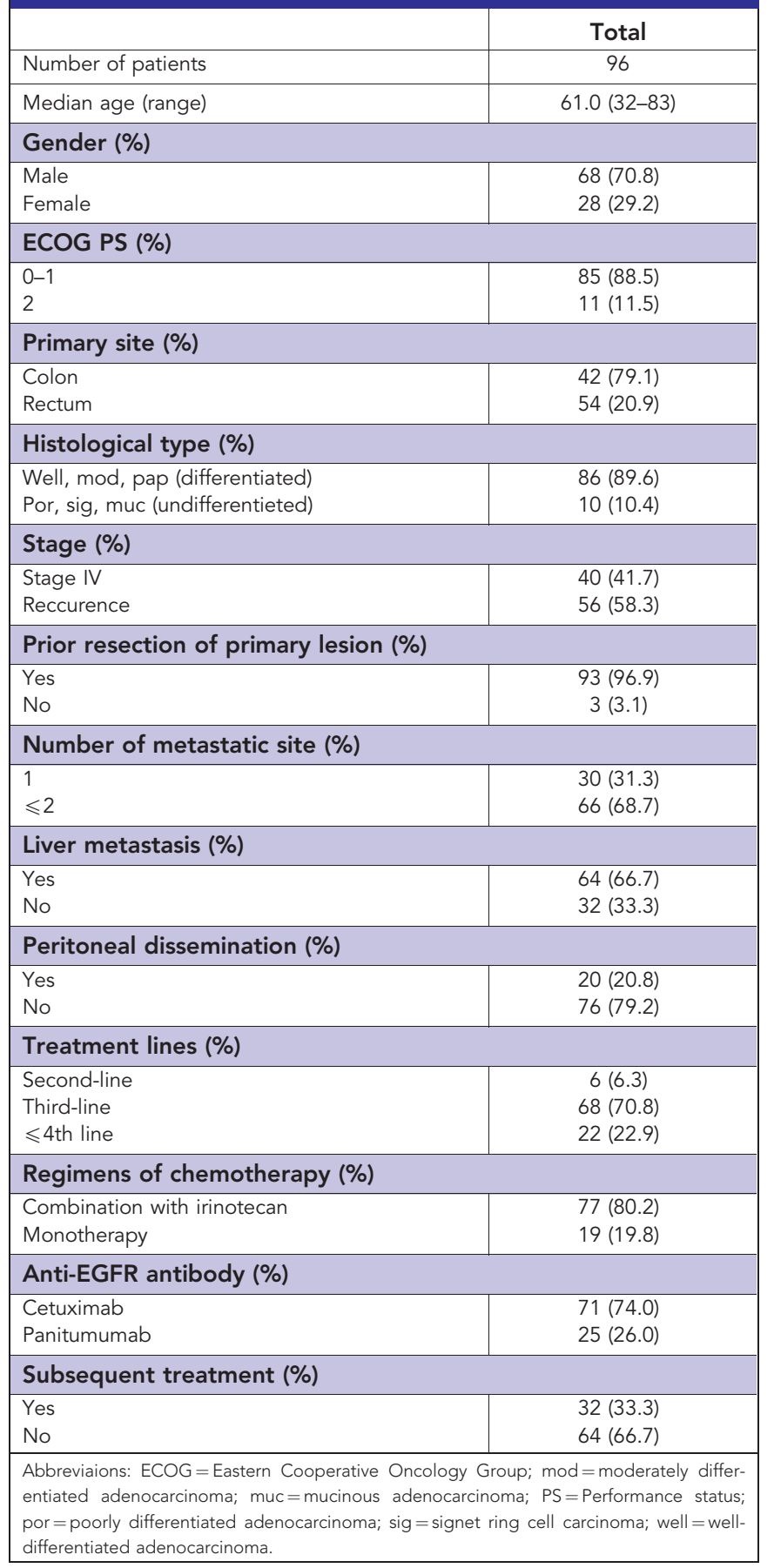

respective mRNA levels of each gene in both T and NT sections are summarised in Supplementary Material 2. The relative mRNA value of AREG could not be calculated in most cases as the expression of this gene generally undetectable in NT sections. Accordingly, the prognostic role of AREG expression was evaluated by utilising the data from tumour tissue sections alone.

The distribution of relative mRNA values for each gene of interest is shown in Figure 1. When 4 quartiles were generated based on relative mRNA values for particular genes, the mRNA values for these genes were significantly elevated in the upper $25 \%$ quadrant.

Prognostic analyses of patient's characteristics and relative mRNA values of target genes in relation to PFS and OS. The results of prognostic analyses assessing various patient 
Table 2. Results of relative mRNA values as tumour and non-tumour ratio in patients who were treated with anti-EGFR antibodies

\begin{tabular}{|l|c|c|c|c|c|c|c|}
\hline Relative mRNA values & $\begin{array}{c}\text { ERBB2 } \\
\mathbf{N = 5 8 / 9 6}\end{array}$ & $\begin{array}{c}\text { MET } \\
\mathbf{N = 6 0 / 9 6}\end{array}$ & $\begin{array}{c}\text { PTEN } \\
\mathbf{N = 6 5 / 9 6}\end{array}$ & $\begin{array}{c}\text { VEGFA } \\
\mathbf{N = 7 8 / 9 6}\end{array}$ & $\begin{array}{c}\text { ERCC1 } \\
\mathbf{N = 8 0 / 9 6}\end{array}$ & $\begin{array}{c}\text { EREG } \\
\mathbf{N = 6 0 / 9 6}\end{array}$ & $\begin{array}{c}\text { AREG } \\
\mathbf{N}=\mathbf{4 0 / 9 6}\end{array}$ \\
\hline Median & 0.620 & 0.905 & 0.688 & 0.690 & 0.486 & 0.408 & 42.25 \\
\hline Range & $0.0011-32.228$ & $0.030-568.165$ & $0.0040-17.875$ & $0.00031-33.823$ & $0.0015-75.059$ & $0.00025-216.747$ & $0.418-3.083$ \\
\hline $\begin{array}{l}\text { Abbreviations: AREG = amphiregulin; EREG = epiregulin. } \\
\text { a } \text { mRNA values of AREG in tumour section are shown because mRNA values of AREG in non-tumour sections were below lower limit of measurable range in most cases. }\end{array}$ \\
\hline
\end{tabular}
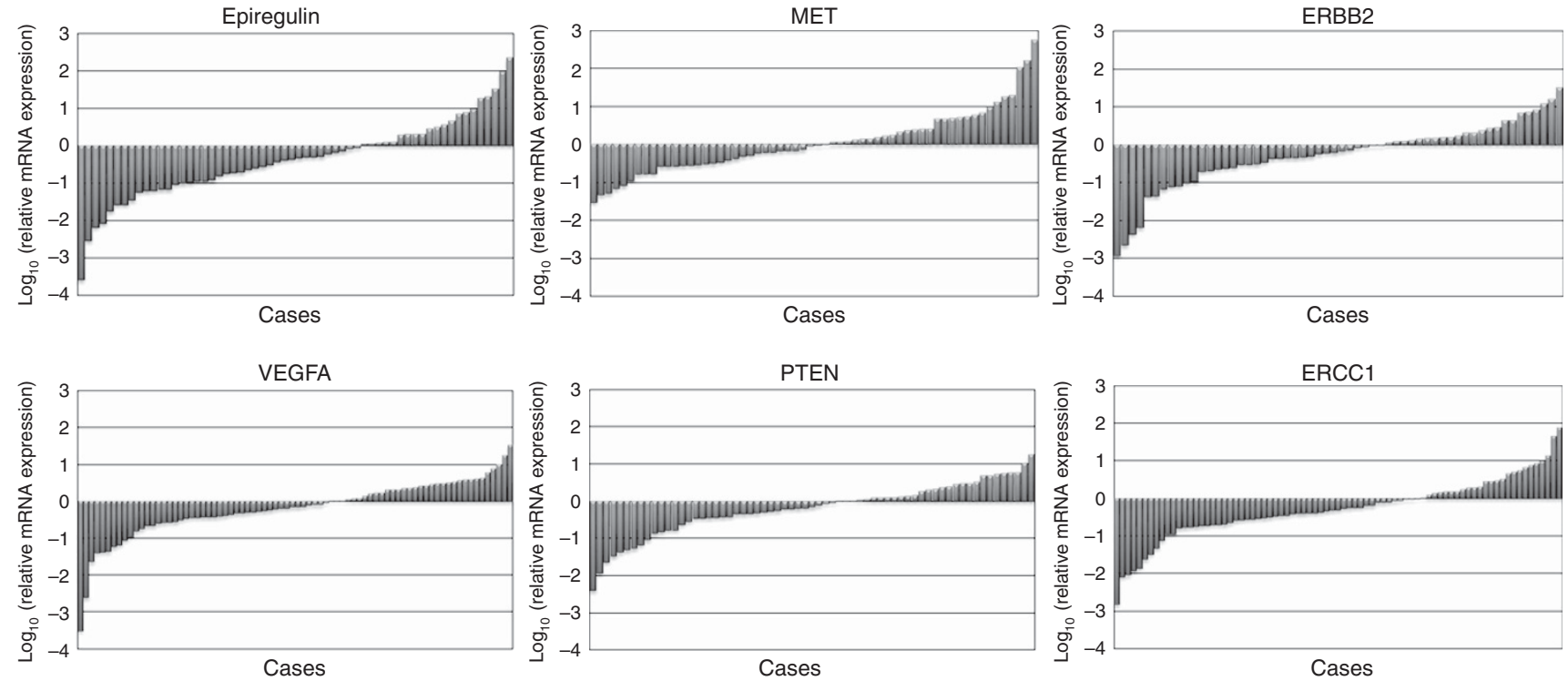

Figure 1. Relative value of mRNA expression of target genes. Relative mRNA values of target genes were expressed as 'tumour ddCt Rel Qty/ non-tumour ddCt Rel Qty' where dCt is the difference between the gene of the target and the GAPDH gene, and ddCT is the difference between the $\mathrm{dCT}$ for each sample and the control group.

characteristics are shown in Table 3. ECOG-PS 2 (HR 3.035, 95\% CI: $1.502-6.130, P=0.002$ ), peritoneal dissemination (HR 1.717, 95\% CI: $1.008-2.927, P=0.046)$, treatment (HR 0.388, 95\% CI: $0.244-0.672, P=0.001$ ) and minor $K R A S / N R A S$ mutation (HR: $0.390,95 \%$ CI: $0.205-0.733, P=0.004)$ were identified as prognostic factors of PFS by univariate analyses. In addition, prognostic factors relevant to OS were determined as ECOG-PS 2 (HR 4.805, 95\% CI: 2.121-10.887, $P<0.001$ ), peritoneal dissemination (HR 1.966, 95\% CI: 1.070-3.613, $P=0.029$ ), and treatment (HR 0.352, 95\% CI: $0.190-0.652, P=0.001$ ).

In order to investigate the optimal cutoff levels of relative mRNA values, adjusted HRs of target genes were calculated according to the 25th, 50th (median) and 75th percentile of relative mRNA value of each gene. When the cutoff level of each gene was determined as the 25th percentile of relative mRNA values, there was no difference in terms of PFS and OS for any of the target genes assessed. Although high relative mRNA values for MET were associated with shorter PFS compared with low MET when the cutoff values were median, relative mRNA values of the other genes were not associated with prognosis when this particular cutoff value was utilised. The results of prognostic analyses of each gene at the 75 th percentile are summarised in Table 4 . The cutoff value of each gene at 75th percentile were 1.933 (EREG), 1.742 (ERBB2), 2.346 (MET), 2.298 (VEGF-A), 1.841 (PTEN) and 1.505 (ERCC1), respectively. HRs of each gene were adjusted according to age, gender, ECOG-PS and other clinicopathological variables, which exhibited $P$-values $<0.1$ on the basis of univariate analysis. Among the target genes assessed, prognostic factors were high level of EREG (HR: $0.326,95 \%$ CI: $0.136-0.772, P=0.011$ ), ERBB2 (HR: $1.31,95 \%$ CI: $1.084-1.652, P=0.040$ ), MET (HR: $2.48,95 \%$ CI: $1.356-5.463, P=0.026$ ), and VEGF-A (HR: $1.29,95 \% \mathrm{CI}$ :
1.036-1.606, $P=0.046)$. Patients with high $E R B B 2$ had shorter PFS compared with those with low ERBB2 (HR: 1.98, 95\% CI: 1.062 $3.850, P=0.042$ ). There were no significant differences in PFS and OS in relation to ERCC1 and PTEN. High expression of AREG in tumour section was associated with shorter OS compared with low AREG (HR: 0.277, 95\% CI: 0.095-0.808, $P=0.019$ ).

There was no significant difference with regards to the frequency of subsequent treatment between subgroups of low and high relative mRNA values of ERBB2 (33.3\% vs 35.7\%), MET (34.9\% vs 33.3\%), VEGFA (37.3\% vs 31.6\%), EREG (35.7\% vs $34.1 \%)$, ERCC1 (33.3\% vs 36.8\%), PTEN (27.1\% vs 29.4\%) and AREG (40.0\% vs $46.7 \%)$.

Survival curves and response according to relative mRNA levels of target genes. Survival curves of PFS and OS according to relative mRNA values of ERBB2, MET and VEGFA (cutoff level: 75th percentile of all patients) in KRAS wild-type patients are shown in Figure 2. High relative mRNA value of ERRB2 was associated with shorter PFS and OS compared with low ERBB2 (median PFS: 4.1 months $v s 9.0$ months, $P=0.032$; median OS: 8.2 months vs 17.1 months, $P=0.043$; log-rank test, respectively). There were significant differences in PFS between high and low levels of MET and VEGFA mRNA. On the other hand, high relative mRNA value of MET was associated with shorter OS compared with low MET (9.8 months vs 17.3 months, $P=0.038$ ). There was no significant difference statistically, but high relative mRNA value of VEGFA had a tendency to be associated with shorter OS compared with low VEGFA (9.8 months vs 14.3 months, $P=0.062)$. There were no significant differences in either PFS or OS when relative mRNA expression values of ERCC1 and PTEN were considered. 
Table 3. Prognostic factors of PFS and OS by univariate analyses in terms of patients' characteristics

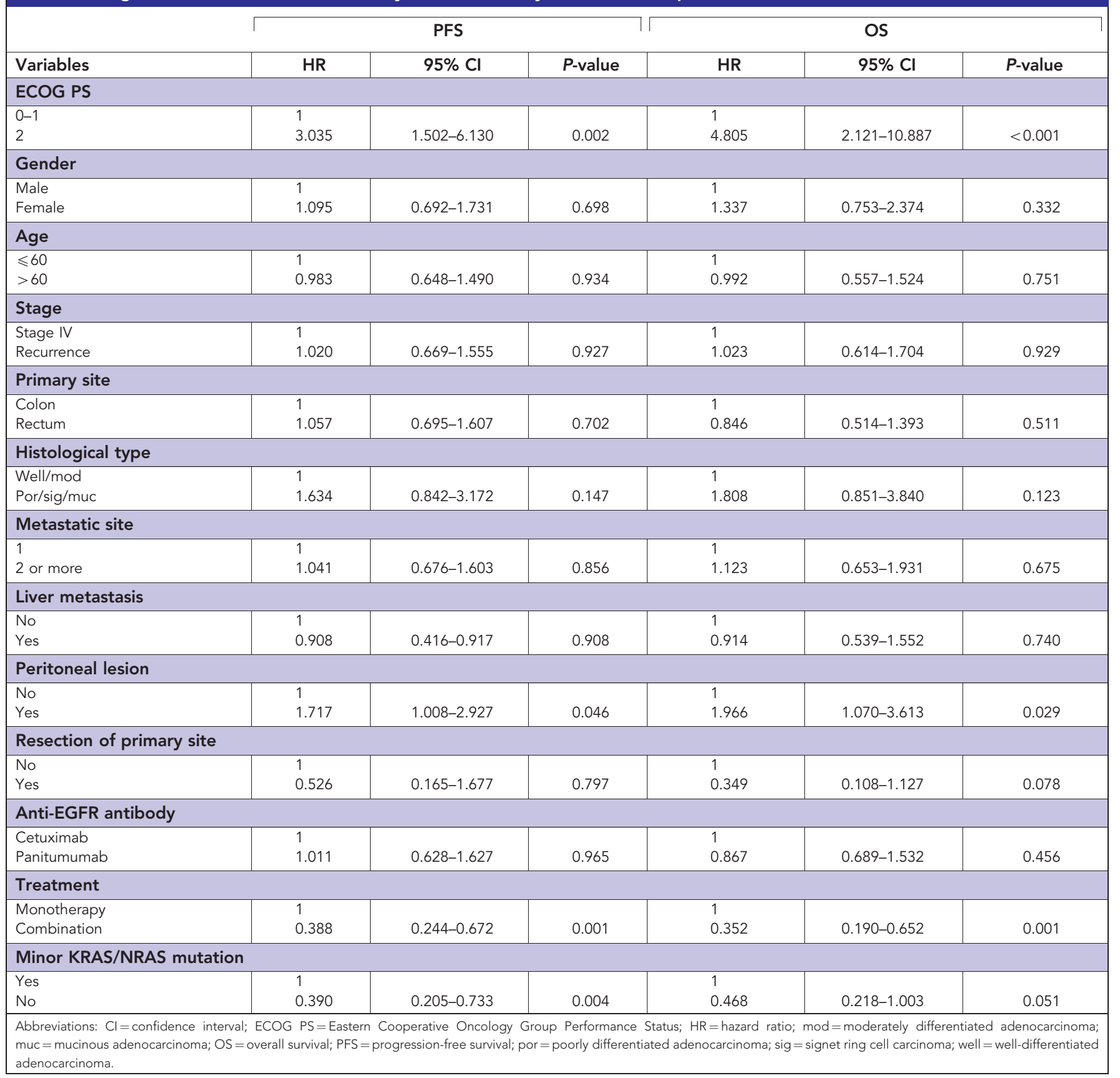

Results relating to links between ORR and relative mRNA values of target genes is provided in Supplementary Material 3. There were no significant differences in ORR when relative mRNA values of target genes were evaluated, but patients having a low relative mRNA value for ERBB2 (13.3\% vs $25.6 \%)$ and EREG $(25.0 \%$ vs $20.5 \%)$ tended to do better than those that did not.

\section{DISCUSSION}

According to previous reports, expression of EREG and $A R E G$ in tumour tissues are recognised as biomarkers to predict the outcome of anti-EGFR antibody treatment in KRAS wild-type patients (Jonker et al, 2007; Van Cutsem et al, 2009; Douillard et al, 2010). In addition to EREG and AREG, our study investigated the prognostic role of ERBB2, MET, VEGFA, PTEN and ERCC1 mRNA expression in tumour $v s$ normal tissue within the same patient, that is T/NT ratio, in a cohort of metastatic CRC patients. High relative mRNA values of ERBB2, MET and VEGFA were associated with worse OS compared with low levels of these genes. These findings indicated the possibility that overexpression of these genes are associated with inherent or acquired resistance to anti-EGFR antibody treatment. Accordingly, inhibitors of such genes may improve the outcome of anti-EGFR antibody treatment in $R A S$ wild-type patients with metastatic CRC. To our knowledge, although this is a study that evaluated several candidate prognostic/ predictive biomarkers via $\mathrm{qRT}-\mathrm{PCR}$ in patients who received first-line chemotherapy with or without cetuximab (Cushman et al, 2015), there are no comparable studies in patients of chemotherapy-refractory metastatic CRC patients treated with anti-EGFR antibodies. 
Table 4. Multivariate analyses of target genes in terms of PFS and OS when cutoff values were determined as 75th percentile of relative mRNA values of each gene

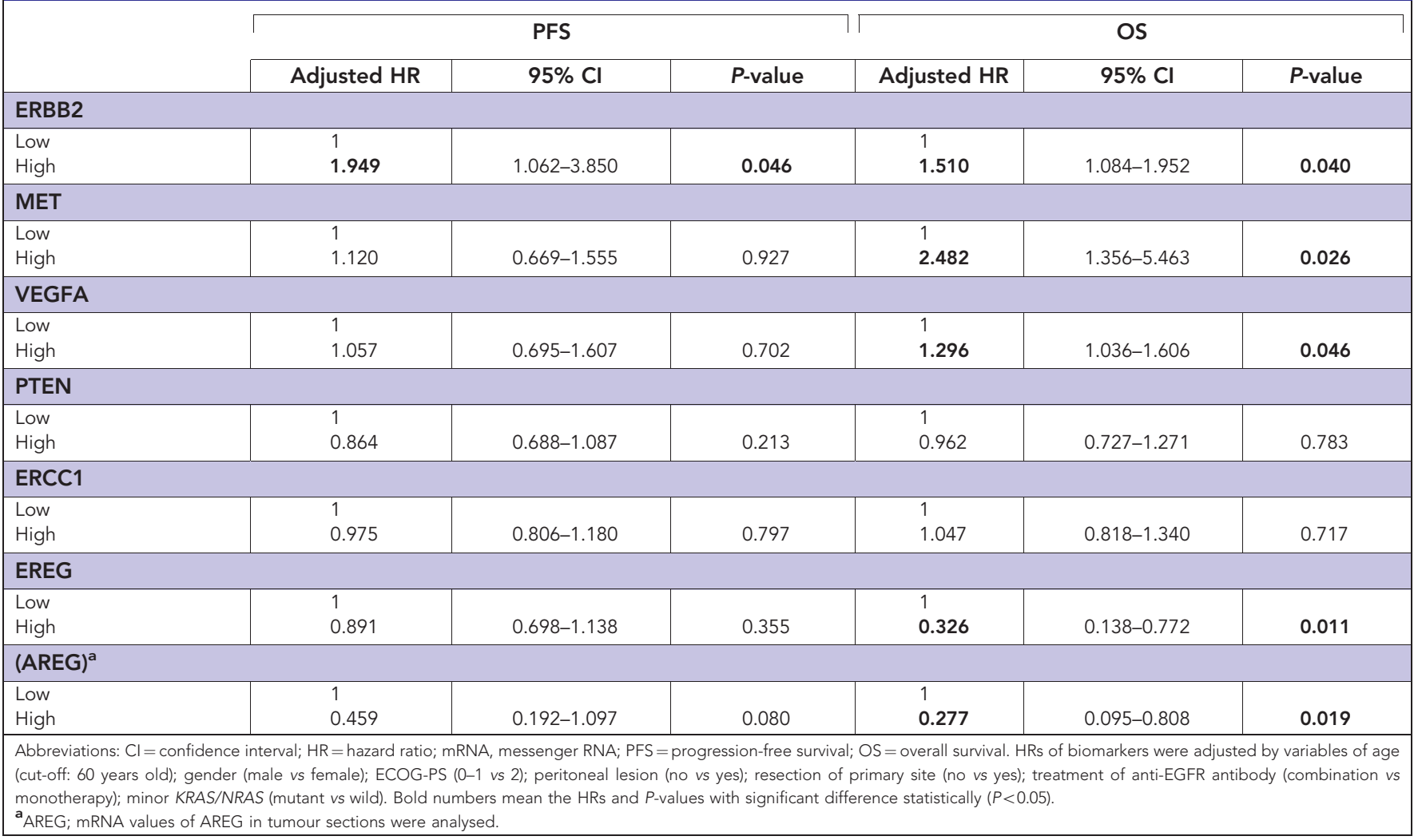
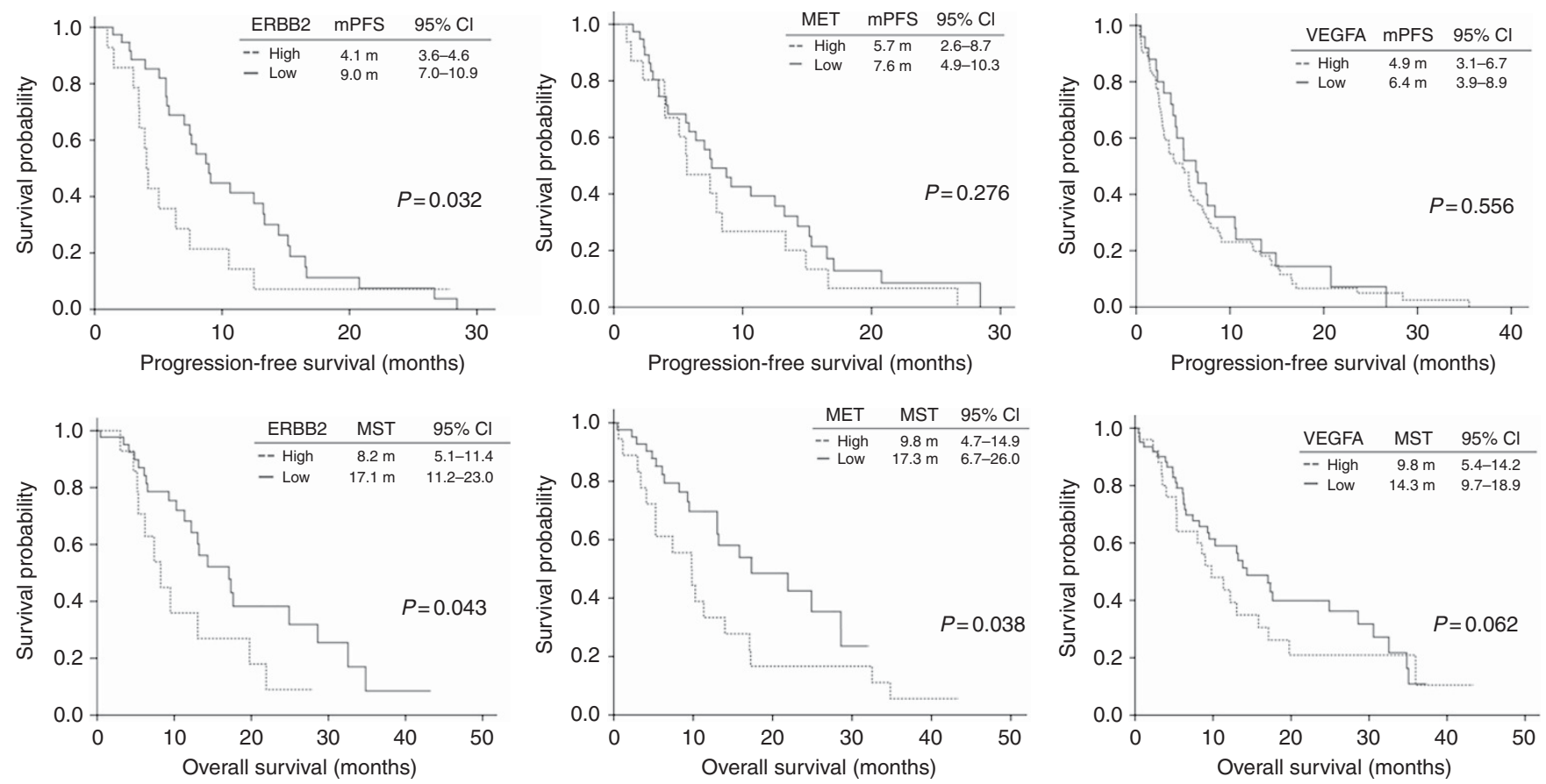

Figure 2. Survival curves of progression-free survival and overall survival according to relative mRNA values (high/low) of ERBB2, MET and VEGFA in KRAS wild-type patients who were treated with anti-EGFR antibodies. MST (Median survival time) - median overall survival.

The ERBB2 (HER2) gene encodes a member of the EGFR family of receptor tyrosine kinases and is located at the long arm of human chromosome 17. In relation to CRC, preclinical research utilising xenopatient models indicated that HER2 amplification is observed specifically in a subset of tumours resistant to cetuximab and exhibiting wild-type KRAS/NRAS/BRAF/PIK3CA (quadruple negative); moreover, analysis of HER2-amplified xenopatients revealed that combination of HER2 and EGFR inhibitors induced long-lasting tumour regression (Bertotti et al, 2011). In this study, HER2 amplification occurs in, respectively, 3\% of metastatic CRC 
patients, $14 \%$ of $K R A S$ wild-type patients and possibly up to $30 \%$ of quadruple negative patients resistant to EGFR-targeted antibodies. In addition, amplification of ERBB2 and ERBB2/ERBB3 signalling promote downstream signalling such as the Akt pathway in cetuximab-resistant CRC cells; in addition, addition of either HER2 or HER3 inhibitors with anti-EGFR antibodies in equivalent xenograft models resulted in tumour regression (Yonesaka et al, 2011; Zhang et al, 2014). These preclinical data support our results and the concept that amplification of the ERBB2 gene confers primary resistance to anti-EGFR antibody treatment, making it a promising target for $R A S / B R A F$ wild-type patients treated with anti-EGFR antibodies. However, the optimal target-population that could obtain clinical benefit from HER2 inhibitors is not $s$ far established by large-scale clinical trials involving CRC patients. In our study, overexpression of the ERBB2 gene in T vs NT tissue sections was detected in a subgroup within the upper 25th percentile of relative mRNA values, with this subgroup being associated with worse PFS and OS following treatment with antiEGFR antibodies. According to previous reports of retrospectively assessed specimens, the frequency of HER2 positivity in CRC as evaluated by overexpression of HER2 protein and amplification of ERBB2 has been reported to range from 2.7 to $47.7 \%$ (Park et al, 2007; Marx et al, 2010; Drebber et al, 2011; Conradi et al, 2013). A recent large-scale cohort study of HER2/neu testing in CRC, utilising the same scoring system as that used in expert guidelines for breast cancer and gastric cancer, showed HER2/neu positivity rate to be 1.6\% (Hofmann et al, 2008; Wolff et al, 2013; Ingold Heppner et al, 2014). Potential reasons of these apparent discrepancies in relation to HER2 positivity rates in CRC include study-specific differences in definition of HER2 positivity, sample size, methodological approach and tissues samples utilised. The HERACRES-A trial, a recent phase II study to evaluate the efficacy and safety profile of combination of trastuzumab and lapatinib in HER2-amplified metastatic CRC patients, revealed that enrolled patients achieved high ORR (34.7\%) and disease control rate (78.3\%) (Siena et al, 2015). In spite of the promising outcome and tolerability profile, the frequency of HER2 amplification observed was only $5.4 \%$, even though this trial included patients with HER2 $\mathrm{IHC} 2+$ and IHC3 + tumours. In addition, half of the HER2amplified patients could not receive treatment with HER2-targeted therapeutics due to poor prognosis and tumour complications after failure of standard chemotherapy. Going forward, definition of an optimal cut-off value and methodological approach for determination HER2 amplification, along with adequate treatment regimens incorporating HER2 inhibitors, is required for the appropriate development of clinical trials in HER2-amplified patients with metastatic CRC.

In the present study, a high level of MET mRNA expression was associated with shorter survival, whereas there is no significant association between expression of this gene and response to anti-EGFR therapy. This may indicate that overexpression of the MET gene is not relevant for primary resistance to anti-EGFR antibody treatment, but it may be linked to acquired resistance to anti-EGFR antibody usage in metastatic CRC patients. With respect to resistance mechanisms relating to anti-EGFR antibody treatment, previous reports indicated that ligand-dependent MET activation contributes to cetuximab resistance in colon cancer (Liska et al, 2011; Troiani et al, 2013). Bardelli et al (2013) reported that amplification of the MET locus was detected in circulating tumour DNA before relapse from treatment with anti-EGFR antibody was clinically confirmed. Other than MET expression, co-expression of the MET gene and HGF is associated with advanced stage and poor survival in CRC (Kammula et al, 2007). In addition, we previously described that a high level of serum HGF was associated with worse outcome following anti-EGFR antibody treatment in KRAS wild-type patients (Takahashi et al, 2014).
It seems that the addition of HGF can further trigger METinitiated signalling and cause resistance to anti-EGFR antibody treatment. Actually, combination of panitumumab and anti-HGF antibody (rilotumumab) induced better response compared with panitumumab monotherapy in KRAS wild-type patients in a recent phase Ib/II trial (Van Cutsem et al, 2014). Further investigation of biomarkers within the HGF/MET pathway, including downstream factors, is needed to aid the development of molecularly targeted drugs relevant to this pathway in CRC.

VEGFA is a major ligand against VEGF receptor and causes the angiogenesis of tumour tissues, as well as enhancing tumour invasion and distal metastasis. Our study indicated that patients with VEGFA-amplified tumours had shorter OS compared with those without VEGFA-amplified tumours. In preclinical studies, increased VEGF expression in CRC tumour cells has a role in the development of anti-EGFR therapy resistance (Viloria-Petit et al, 2001; Ellis, 2004). In addition, chronic administration of EGFR inhibitors to mice with colon cancer xenografts induced resistant cells with increased VEGF expression; notably, VEGF receptortargeting tyrosine kinase inhibitors achieved anti-tumour activity against those xenografts exhibiting resistance to EGFR inhibitor (Ciardiello et al, 2004). In a recent phase II trial, combination of TAS-102 and bevacizumab showed both a good efficacy and safety profile in metastatic CRC patients after failure of standard therapies including anti-EGFR antibody and anti-VEGF antibody usage (Kuboki et al, 2015). It is possible that patients with VEGFamplified tumours may comprise a particular subgroup that obtains clinical benefit from a strategy employing bevacizumab beyond progression (BBP) or rechallenge of chemotherapy with anti-VEGF antibodies.

There are some limitations to the present study. First, this study is retrospective in nature and patients without adequate tissue samples for qRT-PCR analysis were excluded, which may cause a potential selection bias. Further validation of our findings via other translational research studies, including those of prospective nature, are required. Second, there were several cases that exhibited no amplification of target genes by qRT-PCR analysis. One of the contributory reasons may be inadequate quality control of tumour tissue samples, such as discrepancies in relation to time utilised for formalin fixation between cases. In addition, AREG gene expression in certain contexts, for example, normal tissues, were lower compared with the expression of other target genes in present study. To address this, a digital PCR system may be better method to facilitate absolute quantification of infrequent or lowly expressed genes in tumour tissues. This system has many potential advantages such as the capability to obtain absolute quantification without external references and robustness to variations in PCR efficiency (Baker, 2012). Third, survival time after failure of antiEGFR antibody in present study may be affected by the recent approved drugs such as regorafenib or TAS102 as salvage-line chemotherapy (Grothey et al, 2013; Mayer et al, 2015). There is no significant difference between high and low levels of relative mRNA value of each gene in the frequency of subsequent treatment after failure of anti-EGFR antibody, but five patients received these drugs and might tend to achieve long survival in present study.

In conclusion, overexpression of ERBB2, MET and VEGFA genes as the T/NT ratio of mRNA level of each gene in tumour tissues were associated with worse prognosis on the treatment of anti-EGFR antibody in metastatic CRC patients. As development of precision medicine, our findings may contribute the novel strategy of combination or sequential use of molecular target drugs of these genes on the treatment of anti-EGFR antibody in RAS wild-type patients. In addition, further research of optimal predictive markers of these genes and validation study are also required in the future. 


\section{ACKNOWLEDGEMENTS}

We appreciate very much the participation of patients and their families in this study, and we thank all co-investigators for their contributions: Ms. Hideko Morita (preparing samples), Mr Atsushi Kakimoto (measurement/analyses) and Mrs Eri Onishi (Supports of clinical research).

\section{CONFLICT OF INTEREST}

The authors declare no conflict of interest.

\section{REFERENCES}

Baker M (2012) Digital PCR hits its stride. Nat Methods 9: 541-544.

Bang YJ, Van Cutsem E, Feyereislova A, Chung HC, Shen L, Sawaki A, Lordick F, Ohtsu A, Omuro Y, Satoh T, Aprile G, Kulikov E, Hill J, Lehle M, Rüschoff J, Kang YK. ToGA Trial Investigators (2010) Trastuzumab in combination with chemotherapy $v s$ chemotherapy alone for treatment of HER2-positive advanced gastric or gastro-oesophageal junction cancer (ToGA): a phase 3, open-label, randomised controlled trial. Lancet 376: 687-697.

Bardelli A, Corso S, Bertotti A, Hobor S, Valtorta E, Siravegna G, Sartore-Bianchi A, Scala E, Cassingena A, Zecchin D, Apicella M, Migliardi G, Galimi F, Lauricella C, Zanon C, Perera T, Veronese S, Corti G, Amatu A, Gambacorta M, Diaz Jr LA, Sausen M, Velculescu VE, Comoglio P, Trusolino L, Di Nicolantonio F, Giordano S, Siena S (2013) Amplification of the MET receptor drives resistance to anti-EGFR therapies in colorectal cancer. Cancer Discov 3: 658-673.

Bertotti A, Migliardi G, Galimi F, Sassi F, Torti D, Isella C, Cora' D, Di Nicolantonio F, Buscarino M, Petti C, Ribero D, Russolillo N, Muratore A, Massucco P, Pisacane A, Molinaro L, Valtorta E, Sartore-Bianchi A, Risio M, Capussotti L, Gambacorta M, Siena S, Medico E, Sapino A, Marsoni S, Comoglio PM, Bardelli A, Trusolino L (2011) A molecularly annotated platform of patient-derived xenografts ('xenopatients') identifies HER2 as an effective therapeutic target in cetuximab-resistant colorectal cancer. Cancer Discov 1: 508-523.

Birchmeier C, Birchmeier W, Gherardi E, Vande Woude GF (2003) Met, metastasis, motility and more. Nat Rev Mol Cell Biol 4: 915-925.

Blanco-Aparicio C, Renner O, Leal JF, Carnero A (2007) PTEN, more than the AKT pathway. Carcinogenesis 28: 1379-1386.

Ciardiello F, Bianco R, Caputo R, Caputo R, Damiano V, Troiani T, Melisi D, De Vita F, De Placido S, Bianco AR, Tortora G (2004) Antitumor activity of ZD6474, a vascular endothelial growth factor receptor tyrosine kinase inhibitor, in human cancer cells with acquired resistance to antiepidermal growth factor receptor therapy. Clin Cancer Res 10: 784-793.

Conradi LC, Styczen H, Sprenger T, Wolff HA, Rodel C, Nietert M, Homayounfar K, Gaedcke J, Kitz J, Talaulicar R, Becker H, Ghadimi M, Middel P, Beissbarth T, Ruschoff J, Liersch T (2013) Frequency of HER-2 positivity in rectal cancer and prognosis. Am J Surg Pathol 37: 522-531.

Cushman SM, Jiang C, Hatch AJ, Shterev I, Sibley AB, Niedzwiecki D, Venook AP, Owzar K, Hurwitz HI, Nixon AB (2015) Gene expression markers of efficacy and resistance to cetuximab treatment in metastatic colorectal cancer: results from CALGB 80203 (Alliance). Clin Cancer Res 21: $1078-1086$

Douillard JY, Oliner KS, Siena S, Tabernero J, Burkes R, Barugel M, Humblet Y, Bodoky G, Cunningham D, Jassem J, Rivera F, Kocákova I, Ruff P, Błasińska-Morawiec M, Šmakal M, Canon JL, Rother M, Williams R, Rong A, Wiezorek J, Sidhu R, Patterson SD (2013) Panitumumab-FOLFOX4 treatment and RAS mutations in colorectal cancer. N Engl J Med 369: 1023-1034.

Douillard JY, Siena S, Cassidy J, Tabernero J, Burkes R, Barugel M, Humblet Y, Bodoky G, Cunningham D, Jassem J, Rivera F, Kocákova I, Ruff P, Błasińska-Morawiec M, Šmakal M, Canon JL, Rother M, Oliner KS, Wolf M, Gansert J (2010) Randomized, phase III trial of panitumumab with infusional fluorouracil, leucovorin, and oxaliplatin (FOLFOX4) vs FOLFOX4 alone as first-line treatment in patients with previously untreated metastatic colorectal cancer: the PRIME study. J Clin Oncol 28: 4697-4705.
Drebber U, Madeja M, Odenthal M, Wedemeyer I, Monig SP, Brabender J, Bollschweiler E, Holscher AH, Schneider PM, Dienes HP, Vallbohmer D (2011) $\beta$-catenin and Her2/neu expression in rectal cancer: association with histomorphological response to neoadjuvant therapy and prognosis. Int J Colorectal Dis 26: 1127-1134.

Ellis LM (2004) Epidermal growth factor receptor in tumor angiogenesis. Hematol Oncol Clin North Am 18: 1007-1021.

Grothey A, Van Cutsem E, Sobrero A, Siena S, Falcone A, Ychou M, Humblet Y, Bouché O, Mineur L, Barone C, Adenis A, Tabernero J, Yoshino T, Lenz HJ, Goldberg RM, Sargent DJ, Cihon F, Cupit L, Wagner A, Laurent D. CORRECT Study Group (2013) Regorafenib monotherapy for previously treated metastatic colorectal cancer (CORRECT): an international, multicentre, randomised, placebocontrolled, phase 3 trial. Lancet 381: 303-312.

Hofmann M, Stoss O, Shi D, Buttner R, van de Vijver M, Kim W, Ochiai A, Ruschoff J, Henkel T (2008) Assessment of a HER2 scoring system for gastric cancer: results from a validation study. Histopathology 52: 797-805.

Hurwitz H, Fehrenbacher L, Novotny W, Cartwright T, Hainsworth J, Heim W, Berlin J, Baron A, Griffing S, Holmgren E, Ferrara N, Fyfe G, Rogers B, Ross R, Kabbinavar F (2004) Bevacizumab plus irinotecan, fluorouracil, and leucovorin for metastatic colorectal cancer. $N$ Engl J Med 350: 2335-2342.

Ingold Heppner B, Behrens HM, Balschun K, Haag J, Krüger S, Becker T, Röcken C (2014) HER2/neu testing in primary colorectal carcinoma. Br J Cancer 111: 1977-1984.

Jacobs B, De Roock W, Piessevaux H, Van Oirbeek R, Biesmans B, De Schutter J, Fieuws S, Vandesompele J, Peeters M, Van Laethem JL, Humblet Y, Pénault-Llorca F, De Hertogh G, Laurent-Puig P, Van Cutsem E, Tejpar S (2009) Amphiregulin and epiregulin mRNA expression in primary tumors predicts outcome in metastatic colorectal cancer treated with cetuximab. J Clin Oncol 27: 5068-5074.

Jemal A, Bray F, Center MM, Ferlay J, Ward E, Forman D (2011) Global cancer statistics. CA Cancer J Clin 61: 69-90.

Jonker DJ, Karapetis CS, Harbison C, O'Callaghan CJ, Tu D, Simes RJ, Malone DP, Langer C, Tebbutt N, Price TJ, Shapiro J, Siu LL, Wong RP, Bjarnason G, Moore MJ, Zalcberg JR, Khambata-Ford S (2014) Epiregulin gene expression as a biomarker of benefit from cetuximab in the treatment of advanced colorectal cancer. Br J Cancer 110: 648-655.

Jonker DJ, O'Callaghan CJ, Karapetis CS, Zalcberg JR, Tu D, Au HJ, Berry SR, Krahn M, Price T, Simes RJ, Tebbutt NC, van Hazel G, Wierzbicki R, Langer C, Moore MJ (2007) Cetuximab for the treatment of colorectal cancer. N Engl J Med 357: 2040-2048.

Kammula US, Kuntz EJ, Francone TD, Zeng Z, Shia J, Landmann RG, Paty PB, Weiser MR (2007) Molecular co-expression of the c-Met oncogene and hepatocyte growth factor in primary colon cancer predicts tumor stage and clinical outcome. Cancer Lett 248: 219-228.

Khambata-Ford S, Garrett CR, Meropol NJ, Basik M, Harbison CT, Wu S, Wong TW, Huang X, Takimoto CH, Godwin AK, Tan BR, Krishnamurthi SS, Burris 3rd HA, Poplin EA, Hidalgo M, Baselga J, Clark EA, Mauro DJ (2007) Expression of epiregulin and amphiregulin and K-ras mutation status predict disease control in metastatic colorectal cancer patients treated with cetuximab. J Clin Oncol 25: 3230-3237.

Kuboki Y, Nishina T, Shinozaki E, Yamazaki K, Shitara K, Okamoto W, Kajiwara T, Matsumoto T, Tsushima T, Mochizuki N, Fukutani M, Nakamoto M, Hasegawa H, Sugama A, Nomura S, Sato A, Ohtsu A, Yoshino T (2015) An investigator initiated multicenter phase I/II study of TAS-102 with bevacizumab for metastatic colorectal cancer refractory to standard therapies (C-TASK FORCE). J Clin Oncol 33, (suppl; abstr 3544).

Lesko E, Majka M (2008) The biological role of HGF-MET axis in tumor growth and development of metastasis. Front Biosci 13: 1271-1280.

Liska D, Chen CT, Bachleitner-Hofmann T, Christensen JG, Weiser MR (2011) HGF rescues colorectal cancer cells from EGFR inhibition via MET activation. Clin Cancer Res 17: 472-482.

Loupakis F, Pollina L, Stasi I, Ruzzo A, Scartozzi M, Santini D, Masi G, Graziano F, Cremolini C, Rulli E, Canestrari E, Funel N, Schiavon G, Petrini I, Magnani M, Tonini G, Campani D, Floriani I, Cascinu S, Falcone A (2009) PTEN expression and KRAS mutations on primary tumors and metastases in the prediction of benefit from cetuximab plus irinotecan for patients with metastatic colorectal cancer. J Clin Oncol 27: 2622-2629.

Marx AH, Burandt EC, Choschzick M, Simon R, Yekebas E, Kaifi JT, Mirlacher M, Atanackovic D, Bokemeyer C, Fiedler W, Terracciano L, 
Sauter G, Izbicki JR (2010) Heterogenous high-level HER-2 amplification in a small subset of colorectal cancers. Hum Pathol 41: 1577-1585.

Mayer RJ, Van Cutsem E, Falcone A, Yoshino T, Garcia-Carbonero R, Mizunuma N, Yamazaki K, Shimada Y, Tabernero J, Komatsu Y, Sobrero A, Boucher E, Peeters M, Tran B, Lenz HJ, Zaniboni A, Hochster H, Cleary JM, Prenen H, Benedetti F, Mizuguchi H, Makris L, Ito M, Ohtsu A. RECOURSE Study Group (2015) Randomized trial of TAS-102 for refractory metastatic colorectal cancer. N Engl J Med 372: 1909-1919.

Park DI, Kang MS, Oh SJ, Kim HJ, Cho YK, Sohn CI, Jeon WK, Kim BI, Han WK, Kim H, Ryu SH, Sepulveda AR (2007) HER-2/neu overexpression is an independent prognostic factor in colorectal cancer. Int J Colorectal Dis 22: 491-497.

Price TJ, Peeters M, Kim TW, Li J, Cascinu S, Ruff P, Suresh AS, Thomas A, Tjulandin S, Zhang K, Murugappan S, Sidhu R (2014) Panitumumab vs cetuximab in patients with chemotherapy-refractory wild-type KRAS exon 2 metastatic colorectal cancer (ASPECCT): a randomised, multicentre, open-label, non-inferiority phase 3 study. Lancet Oncol 15: 569-579.

Saltz LB, Clarke, Diaz Rubio E, Scheithauer W, Figer A, Wong R, Koski S, Lichinitser M, Yang TS, Rivera F, Couture F, Sirzén F, Cassidy J (2008) Bevacizumab in combination with oxaliplatin-based chemotherapy as first-line therapy in metastatic colorectal cancer: a randomized phase III study. J Clin Oncol 26: 2013-2019.

Siena S, Sartore-Bianchi A, Lonardi S, Trusolino L, Martino C, Bencardino K, Leone F, Zagonel V, Valtorta E, Torri V, Siravegna G, Amatu A, Francesca Bonazzina E, Rusconi F, Ghezzi S, Ciardiello F, Veronese S, Maria Comoglio P, Bardelli A, Marsoni S (2015) Trastuzumab and lapatinib in HER2-amplified metastatic colorectal cancer patients (mCRC): The HERACLES trial. J Clin Oncol 33(suppl): abstr 3508.

Slamon DJ, Leyland-Jones B, Shak S, Fuchs H, Paton V, Bajamonde A, Fleming T, Eiermann W, Wolter J, Pegram M, Baselga J, Norton L (2001) Use of chemotherapy plus a monoclonal antibody against HER2 for metastatic breast cancer that overexpresses HER2. N Engl J Med 344: 783-792.

Takahashi N, Yamada Y, Furuta K, Honma Y, Iwasa S, Takashima A, Kato K, Hamaguchi T, Shimada Y (2014) Serum levels of hepatocyte growth factor and epiregulin are associated with the prognosis on anti-EGFR antibody treatment in KRAS wild-type metastatic colorectal cancer. Br J Cancer 110: 2716-2727.

Troiani T, Martinelli E, Napolitano S, Vitagliano D, Ciuffreda LP, Costantino S, Morgillo F, Capasso A, Sforza V, Nappi A, De Palma R, D'Aiuto E, Berrino L, Bianco R, Ciardiello F (2013) Increased TGF- $\alpha$ as a mechanism of acquired resistance to the anti-EGFR inhibitor cetuximab through EGFR-MET interaction and activation of MET signaling in colon cancer cells. Clin Cancer Res 19: 6751-6765.

Van Cutsem E, Eng C, Nowara E, Swieboda-Sadlej A, Tebbutt NC, Mitchell E, Davidenko I, Stephenson J, Elez E, Prenen H, Deng H, Tang R, McCaffery I, Oliner KS, Chen L, Gansert J, Loh E, Smethurst D, Tabernero J (2014) Randomized phase Ib/II trial of rilotumumab or ganitumab with panitumumab $v s$ panitumumab alone in patients with wild-type KRAS metastatic colorectal cancer. Clin Cancer Res 20: 4240-4250.

Van Cutsem E, Köhne CH, Hitre E, Zaluski J, Chang Chien CR, Makhson A, D’Haens G, Pintér T, Lim R, Bodoky G, Roh JK, Folprecht G, Ruff P, Stroh C, Tejpar S, Schlichting M, Nippgen J, Rougier P (2009) Cetuximab and chemotherapy as initial treatment for metastatic colorectal cancer. $N$ Engl J Med 360: 1408-1417.

Van Cutsem E, Köhne CH, Láng I, Folprecht G, Nowacki MP, Cascinu S, Shchepotin I, Maurel J, Cunningham D, Tejpar S, Schlichting M, Zubel A, Celik I, Rougier P, Ciardiello F (2011) Cetuximab plus irinotecan, fluorouracil, and leucovorin as first-line treatment for metastatic colorectal cancer: updated analysis of overall survival according to tumor KRAS and BRAF mutation status. J Clin Oncol 29: 2011-2019.

Van Cutsem E, Lenz HJ, Köhne CH, Heinemann V, Tejpar S, Melezínek I, Beier F, Stroh C, Rougier P, van Krieken JH, Ciardiello F (2015) Fluorouracil, leucovorin, and irinotecan plus cetuximab treatment and RAS mutations in colorectal cancer. J Clin Oncol 33: 692-700.

Viloria-Petit A, Crombet T, Jothy S, Hicklin D, Bohlen P, Schlaeppi JM, Rak J, Kerbel RS (2001) Acquired resistance to the antitumor effect of epidermal growth factor receptor-blocking antibodies in vivo: a role for altered tumor angiogenesis. Cancer Res 61: 5090-5101.

Wolff AC, Hammond ME, Hicks DG, Dowsett M, McShane LM, Allison KH, Allred DC, Bartlett JM, Bilous M, Fitzgibbons P, Hanna W, Jenkins RB, Mangu PB, Paik S, Perez EA, Press MF, Spears PA, Vance GH, Viale G, Hayes DF. American Society of Clinical Oncology College of American Pathologists (2013) Recommendations for human epidermal growth factor receptor 2 testing in breast cancer: American Society of Clinical Oncology/College of American Pathologists clinical practice guideline update. J Clin Oncol 31: 3997-4013.

Yonesaka K, Zejnullahu K, Okamoto I, Satoh T, Cappuzzo F, Souglakos J, Ercan D, Rogers A, Roncalli M, Takeda M, Fujisaka Y, Philips J, Shimizu T, Maenishi O, Cho Y, Sun J, Destro A, Taira K, Takeda K, Okabe T, Swanson J, Itoh H, Takada M, Lifshits E, Okuno K, Engelman JA, Shivdasani RA, Nishio K, Fukuoka M, Varella-Garcia M, Nakagawa K, Jänne PA (2011) Activation of ERBB2 signaling causes resistance to the EGFR-directed therapeutic antibody cetuximab. Sci Transl Med 3: 99ra86.

Zhang L, Castanaro C, Luan B, Yang K, Fan L, Fairhurst JL, Rafique A, Potocky TB, Shan J, Delfino FJ, Shi E, Huang T, Martin JH, Chen G, Macdonald D, Rudge JS, Thurston G, Daly C (2014) ERBB3/HER2 signaling promotes resistance to EGFR blockade in head and neck and colorectal cancer models. Mol Cancer Ther 13: 1345-1355.

This work is published under the standard license to publish agreement. After 12 months the work will become freely available and the license terms will switch to a Creative Commons AttributionNonCommercial-Share Alike 4.0 Unported License.

Supplementary Information accompanies this paper on British Journal of Cancer website (http://www.nature.com/bjc) 